\title{
SIQRV Modeli ve Nümerik Uygulaması
}

\author{
Zafer Öztürk $^{1^{*}}$, Sezer Sorgun ${ }^{2}$, Halis Bilgil $^{3}$ \\ 1*Nevşehir Hacı Bektaş Veli Üniversitesi,Fen Bilimleri Enstitüsü, , Matematik Anabilim Dalı, Nevşehir, Türkiye,(ORCID: 0000-0001-5662-4670), \\ zaferozturk@aksaray.edu.tr \\ 2 Nevşehir Hacı Bektaş Veli Üniversitesi, Fen-Edebiyat Fakültesi, Matematik Bölümü, Nevşehir, Türkiye (ORCID: 0000-0001-8708-1226), ssorgun@nevsehir.edu.tr \\ ${ }^{3}$ Aksaray Üniversitesi, Fen-Edebiyat Fakültesi, Matematik Bölümü, Aksaray, Türkiye (ORCID: 0000-0002-8329-5806), halis@aksaray.edu.tr
}

(1st International Conference on Applied Engineering and Natural Sciences ICAENS 2021, November 1-3, 2021)

(DOI: 10.31590/ejosat.1009469)

\begin{abstract}
ATIF/REFERENCE: Öztürk, Z., Sorgun, S. \& Bilgil, H. (2021). SIQRV Modeli ve Nümerik Uygulamas1. Avrupa Bilim ve Teknoloji Dergisi, (28), 573-578.

$\ddot{O} \mathbf{z}$

Hemen hemen tüm dünya genelinde COVID-19 salgının neden olduğu bir pandemik durum söz konusudur. Bu salgının önlenmesi için alınan önlemler ve geliştirilen aşı çalışmalarına rağmen virüsün mutasyona uğrayarak yapısının değişmesiyle birlikte salgının seyri her geçen gün değişim göstermektedir. Uzmanların ortak kanaatleri ise salgınla mücadelenin en önemli silahın aşı olduğu yönündedir. Bu çalışmada $S I Q R$ (Hassas-Enfekte-Karantina-İyileşmiş) salgın hastalık modeline aşılanmış bireyler sınıfı eklenerek yeni bir $S I Q R V$ modeli elde edildi. Yeni oluşturulan $S I Q R V$ modelinde toplam nüfus beş bölüme ayrılmıştır. Duyarlı birey sınıfı $(S)$, enfektif birey sınıfı $(I)$, karantinada olan birey sınıfı $(Q)$, iyileşmiş bireylerin sınıfı $(R)$ ve aşılanmış bireylerin sınıfı $(V)$ ile ilgili matematiksel analizler yapılarak nümerik sonuçlar Euler methodu yardımı ile elde edildi ve grafikler çizildi.
\end{abstract}

Anahtar Kelimeler: SIQRV Modeli, Pandemi, Euler Methodu, Karantina, Aşılama.

\section{SIQRV Model and Numerical Application}

\begin{abstract}
There is a pandemic situation caused by the COVID-19 epidemic almost all over the world. Despite the measures taken to prevent this epidemic and the vaccine studies developed, the course of the epidemic changes day by day as the virus mutates and changes its structure. The common opinion of the experts is that the most important weapon in the fight against the epidemic is the vaccine. In this paper, a new SIQRV model was obtained by adding a class of individuals who have been vaccinated to the $S I Q R$ (susceptible-infectedquarantine-recovered) model. In the newly created $S I Q R V$ model, the total population is divided into five sections. Numerical results were obtained through Euler method and graphs were drawn by mathematical analysis class of the susceptible individual (S), the class of the infected individual (I), the class of the in quarantine $(\mathrm{Q})$, the class of the recovered $(\mathrm{R})$ and the class of the vaccinated individuals (V).
\end{abstract}

Keywords: SIQRV Model, Pandemic, Euler Method, Quarantine, Vaccination. 


\section{Giriş}

Epidemiyoloji; belli toplumlarda sağlıkla ilgili durumların ve olayların saptanması, dağılımının ve nedenlerinin irdelenmesi ile bu incelemelerin sağlık problemlerinin önlenmesi ve kontrolü için yöntemler geliştirmeyi planlayan bilim dalıdır [1]. Belli bir bölgeyi etkileyen salgın hastalıklar epidemik olarak nitelendirilirler. Pandemi ise dünyada birden fazla ülkede veya kıtada, çok geniş bir alanda yayılan ve etkisini gösteren salgın hastalıklara verilen genel isimdir. İlk defa 2019 yılında Çin'in Wuhan şehrinde ortaya çıkan ve kısa sürede tüm dünyayı etkisi altına alan COVID-19 hastalığı neticesinde dünya genelinde çok sayıda ölümler görülmektedir. Halen bu yeni viral hastalığa bağlı olarak, birçok ülke eğitim, ekonomi, sağlık ve turizm gibi birçok alanda zor bir süreç geçirmeye devam etmektedir. COVID-19 salgının hızla tüm dünyayı etkisi almasından dolayı 1 Mart 2020 tarihinde Dünya Sağlık Örgütü (WHO) tarafından pandemi olarak ilan edildi. COVID-19 virüsünün çok hızlı yayılması, mutasyonlar geçirerek güçlenmesi, insanların tedbirlere yeterince özen göstermemesi ve henüz hastalığı önleyecek kesin bir ilacının bulunamamış olması bütün insanlığın endişelerini artırmaya devam etmektedir.

Şüphesiz ki COVID-19 gibi salgın hastalıkların seyri, salgını etkileyen parametrelerle yakından ilgilidir. $\mathrm{Bu}$ parametrelere bağlı matematiksel modeller ise gerek mevcut durum gerekse olabilecek senaryoların takip ve kontrol edilebilmesi için en güvenilir yöntemlerin başında gelmektedir.[2] Bir salgın hastalığın ilerleyiş şekli ve salgında rolü olan faktörlerin pandemi üzerindeki etkilerinin belirlenmesi, ilgili otoriteler için hayati önem taşır. Çünkü yapılacak planlamalardan alınacak önlemlere kadar birçok karar bu sonuçlara bağlıdır. [3]

Enfeksiyon hastalıkları için iyi bilinen ve en sık kullanılan modeller, adi diferansiyel denklem sistemleri tarafindan oluşturulan SI, SIR, SEIR, SIRD, SIQR, SEIQR, SVIR ve SEIRD gibi modellerdir [4-15]. Bu modellerdeki her bir değişken, faklı birer kompartımandaki bireylerin sayısını temsil eder.

$\mathrm{Bu}$ çalışmada popülasyon beş ana kompartımana ayrılarak yeni bir model geliştirilmiştir. Literatürdeki önceki çalışmalardan farklı olarak hem karantinadaki hem de aşılanmış bireylerin kompartımanları aynı modelde yer almıştır. Ayrıca aşının koruyuculuk katsayısı da göz önüne alınarak model güçlendirilmiştir. Makale dört bölümden oluşmakta olup birinci bölüm konunun önemi ve literatür bilgilerinin yer aldığı giriş bölümü olup ikinci bölümde geliştirilen SIQRV modeli verildi. Üçüncü bölümde ise SIQRV modelinin nümerik çözüm mekanizması verilerek örnek problemin çözümü ile açıklayıcı grafiklere yer verildi. Sonuçların yer aldığı dördüncü ve son bölümde ise elde edilen bulgular verildi.

\section{Materyal ve Metot}

\subsection{SIQRV Modeli}

$S I Q R V$ modeli, bir topluluğu temel olarak beş ana gruba ayırır. Birincisi hassas bireyler, ikincisi enfekte olmuş bireyler, üçüncüsü karantinada olan bireyler, dördüncüsü iyileşmiş bireyler ve beşincisi aşılanmış olan bireylerdir. $\mathrm{Bu}$ modelde kullanılan değişkenleri açıklayalım.

\subsubsection{Modelde Kullanılan Değişkenler}

$S, I, Q, R$ ve $V$ gruplarının birey sayılarını diferansiyel denklem sistemi şeklinde ifade edelim.

$$
\begin{aligned}
& \frac{d S}{d t}=b N-b S-\frac{\beta S I}{N}-\sigma S+\theta V+\vartheta R \\
& \frac{d I}{d t}=\frac{\beta S I}{N}-b I-\gamma I-k I+\frac{\beta I V}{N} \\
& \frac{d Q}{d t}=k I-b Q-\gamma Q \\
& \frac{d R}{d t}=\gamma I+\gamma Q-b R-\vartheta R \\
& \frac{d V}{d t}=\sigma S-\theta V-b V-\frac{\beta I V}{N} \\
& S(0)=S_{0}, I(0)=I_{0}, Q(0)=Q_{0}, R(0)=R_{0}, V(0)=V_{0} \\
& S+I+Q+R+V=N . \\
& \frac{d N}{d t}=\frac{d S}{d t}+\frac{d I}{d t}+\frac{d Q}{d t}+\frac{d R}{d t}+\frac{d V}{d t}=0
\end{aligned}
$$

Sistemde kullanılan değişkenler:

$S(t)$ : Popülasyondaki hassas bireylerin sayısı

$I(t)$ : Popülasyondaki enfektif bireylerin sayısı

$Q(t)$ : Popülasyondaki karantinada olan bireylerin sayısı

$R(t)$ : Popülasyondaki bağışıklığa sahip bireylerin sayısı

$V(t)$ : Popülasyondaki aşılanmış bireylerin sayısı

$N(t)$ : Toplam popülasyon sayıs 1

Sistemde kullanılan parametreler:

$\beta$ : Bulaştırma katsayısı

$\sigma:$ Aşılama oranı

$\theta$ : Aşının korumasının düşme oranı

$b$ : Doğum ve ölüm oranı

$\gamma:$ İyileşme oranı

७: İyileşenlerin bağışıklığını kaybetme oranı

$k$ : Enfekte gruptan karantina grubuna geçenlerin oranı 
Popülasyonda dışarıdan göç alımı, dışarıya göç verme yoktur. Ayrıca popülasyondaki her bireyin aynı olasılıkta bulaştırma oranına sahip olduğu kabul edilmiştir. Yaş, cinsiyet, sosyal statü ve ırk enfekte olma olasılığını etkilemektedir. Kalıtsal bağışıklık yoktur. Doğal doğum ve ölüm oranları modele dahil edilmiştir. Tüm doğumlar hassas sınıfa girmiş kabul edilir. [6-7]

$N=200, S=130, Q=10, R=20, V=15$

$\beta=0.6, \gamma=0.25, \vartheta=0.02, k=0.001$,

$b=0.02, \theta=0.005, \sigma=0.55$

parametrelerini ele alalım.

$$
\begin{aligned}
S(k+1)=S(k) & +b N-b S(k)-\frac{\beta S(k) I(k)}{N}-\sigma S(k) \\
& +\theta V(k)+\vartheta R(k) \\
I(k+1)=I(k)+ & \frac{\beta S(k) I(k)}{N}-b I(k)-\gamma I(k)-k I(k) \\
+ & \frac{\beta I(k) V(k)}{N}
\end{aligned}
$$

$Q(k+1)=Q(k)+k I(k)-b Q(k)-\gamma Q(k)$

$R(k+1)=R(k)+\gamma I(k)+\gamma Q(k)-b R(k)-\vartheta R(k)$

$V(k+1)=V(k)+\sigma S(k)-\theta V(k)-b V(k)-\frac{\beta I(k) V(k)}{N}$

Euler methodunu kullanarak her $k=0,1, \ldots, n-1$ için aşağıdaki tabloyu elde ederiz.

\section{Araştırma Sonuçları ve Tartışma 3.1. SIQRV Modelinin Nümerik Simülasyonu}

Bu bölümde $S I Q R V$ modelinin nümerik simülasyonunu ve grafiklerini göstereceğiz. Matematiksel modellerin birçoğu lineer olmayan sistemlerden oluşur ve bu sistemlerin çözümlerinin bulunuşu oldukça zor olabilir. Bu durumda nümerik çözümler

\begin{tabular}{|c|c|c|c|c|c|}
\hline$t$ & $S(t)$ & $I(t)$ & $Q(t)$ & $R(t)$ & $V(t)$ \\
\hline 0 & 130 & 25 & 10 & 20 & 15 \\
\hline 1 & 83.1625 & 18.5875 & 7.325 & 27.95 & 86.0875 \\
\hline 2 & 87.8563 & 13.8219 & 5.3658 & 33.3101 & 116.8027 \\
\hline 3 & 88.6779 & 10.28 & 3.9308 & 36.7746 & 130.6059 \\
\hline 4 & 89.2525 & 7.6473 & 2.8798 & 38.8564 & 137.3311 \\
\hline 5 & 89.6235 & 5.69 & 2.1099 & 39.9339 & 141.0997 \\
\hline 6 & 89.8766 & 4.2347 & 1.5459 & 40.2865 & 143.6334 \\
\hline 7 & 90.055 & 3.1522 & 1.1327 & 40.1202 & 145.6463 \\
\hline 8 & 90.1835 & 2.347 & 0.83 & 39.5867 & 147.4308 \\
\hline 9 & 90.2772 & 1.7479 & 0.6082 & 38.7975 & 149.1033 \\
\hline 10 & 90.3462 & 1.3019 & 0.4458 & 37.8347 & 150.7082 \\
\hline 11 & 90.3973 & 0.97 & 0.3267 & 36.7582 & 152.2610 \\
\hline 12 & 90.4353 & 0.7228 & 0.2394 & 35.6121 & 153.7658 \\
\hline 13 & 90.4635 & 0.5387 & 0.1755 & 34.4282 & 155.2234 \\
\hline 14 & 90.4846 & 0.4016 & 0.1286 & 33.2297 & 156.6331 \\
\hline
\end{tabular}
oldukça önem taşımaktadır. Nümerik yöntemlerden bir tanesi de Euler methodudur. [16]

Tablo 1. $S, I, Q, R$ ve $V$ 'nin t anındaki değerleri. 
Avrupa Bilim ve Teknoloji Dergisi

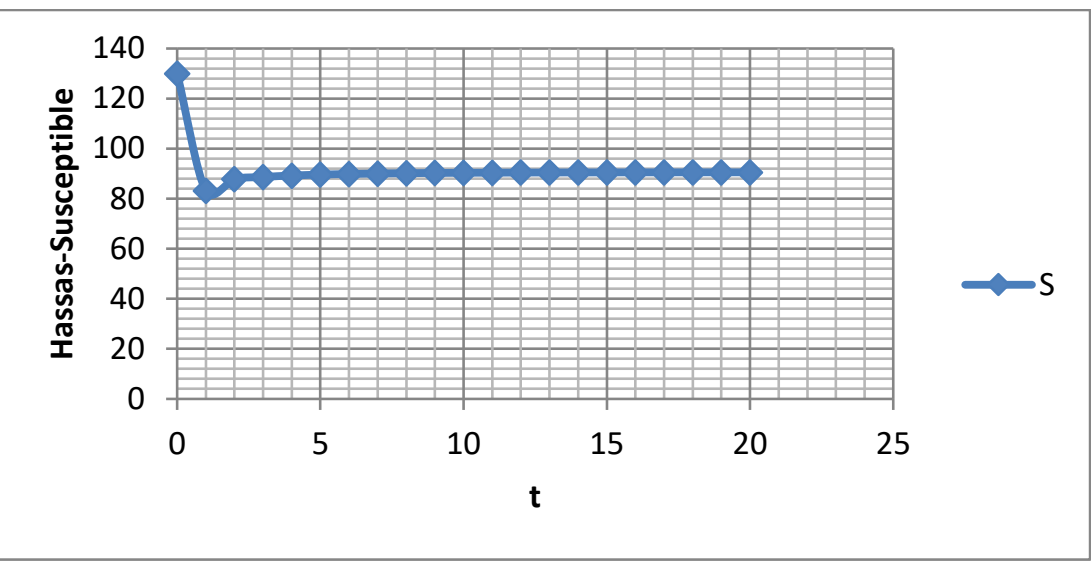

Şekil 1. S Kompartman modelinin zamana göre değişim grafiği

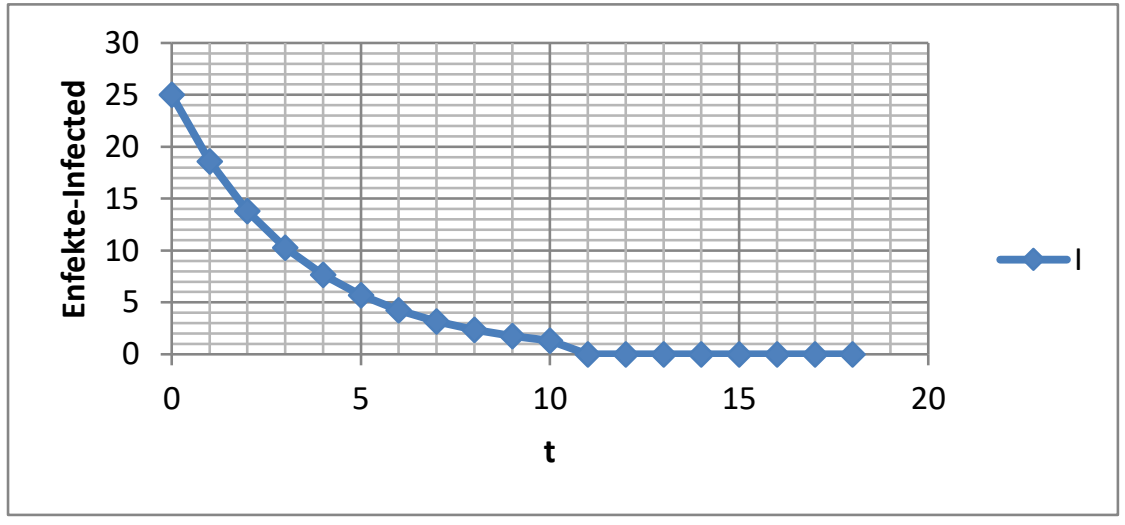

Şekil 2. I Kompartman modelinin zamana göre değişim grafiği

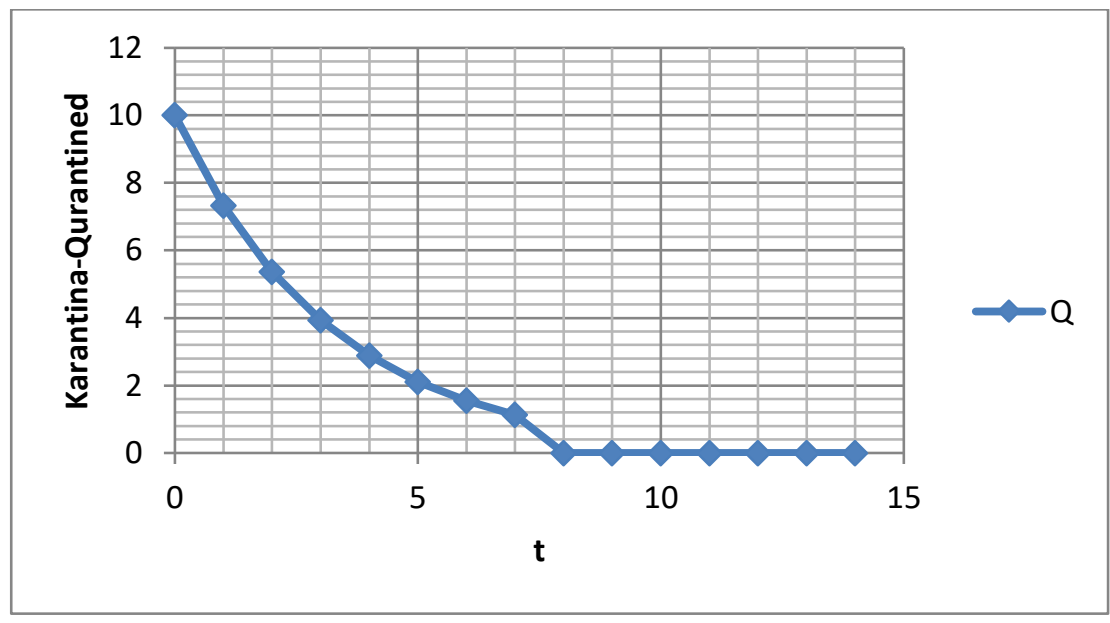

Şekil 3. $Q$ Kompartman modelinin zamana göre değiş̧im grafiği 


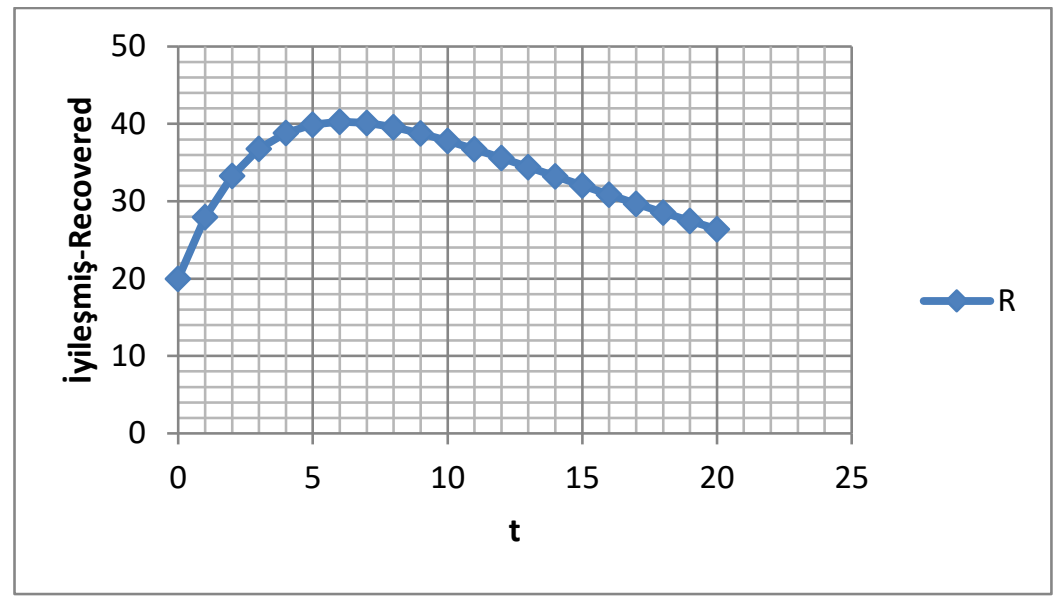

Şekil 4. $R$ Kompartman modelinin zamana göre değişim grafiği

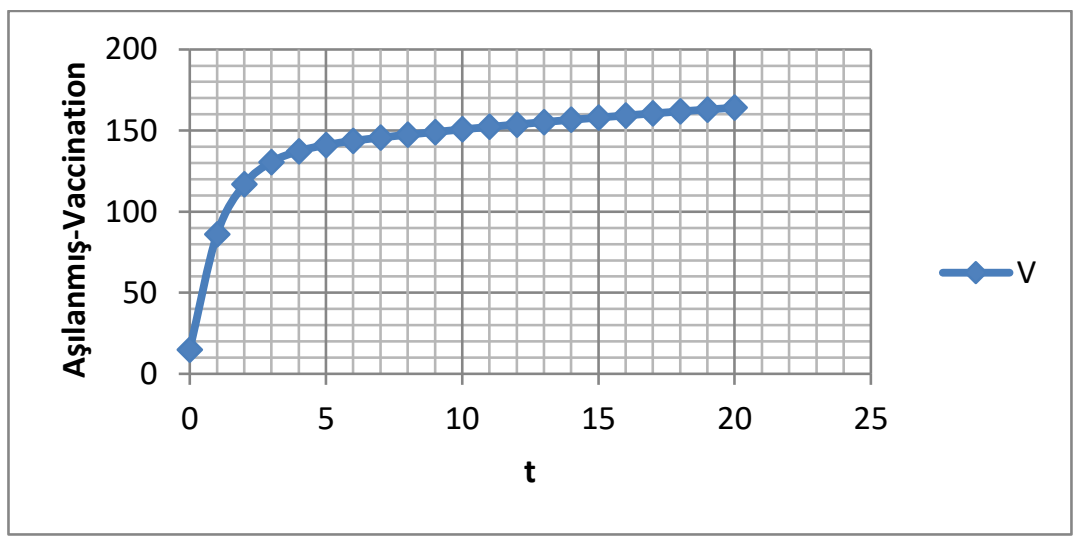

Şekil 5. V Kompartman modelinin zamana göre değişim grafiği

\section{Sonuç}

$\mathrm{Bu}$ çalışmada $S I Q R$ modeline $V$ kompartman modeli eklenerek yeni bir model elde edildi. Aşılama oranı ve aşının koruyuculuğu kaybetme oranı modellemeye dahil edilerek, aşılama ile birlikte salgının ne şekilde değişeceği nümerik simülasyonlar yardımıyla incelendi. Elde edilen grafiklerde hassas bireylerin zamanla azalarak sabit bir şekilde ilerlediği, enfekte bireylerin zamanla azalarak sıfıra yaklaştığı, karantinada olan bireylerin zamanla azalarak sıfıra yaklaştığı, iyileşen bireylerin $\mathrm{t}=5$ zamanında maksimum değerini aldıktan sonra zamanla azaldığı ve aşılanan bireylerin zamanla hızlı bir şekilde arttığı gözlemlenmiştir. Ayrıca aşılama oranının artırılarak salgınla mücadelede önemli yol kat edileceği gerçeği gözlendi.

\section{Kaynakça}

1. Köksal, S.S., 2008. "Epidemiyoloji", Halk Sağlığı Ders Kitabı, Baltaş Z, Ed., İstanbul Üniversitesi, İstanbul, 46-144.

2. Valleron, A. J., 2000. Roles of Mathematical Modeling in Epidemiology, Comptes Rendus de I'Academie des Sciences - Series III- Sciences de la Vie, 323 (5): 429-433.

3. Allen L. J. S., 2007, An Introduction to Mathematical Biology, Department of Mathematics and Statistics, Texas Tech University, Pearson Education., 348.

4. W.O. Kermack and A.G. McKendrick, 1927. A contribution to the mathematical theory of epidemics, in: Proceedings of the
Royal Society of London, Series A, Containing Papers of a Mathematical and Physical Character, 115 (772), 700-721,

5. S.T.A. Shah, M. Mansoor, A.F. Mirza, M. Dilshad, M.I. Khan, R. Farwa, M.A. Khan, M. Bilal and H.M.N. Iqbal, 2020. Predicting COVID-19 spread in Pakistan using the SIR Model, J. Pure Appl. Microbiol. 14 (2), 1423-1430.

6. R. M. Anderson, R. M. May, Infectious Diseases of Humans: Dynamics and Control (Oxford University Press, Oxford, 1991).

7. N. T. J. Bailey, The Mathematical Theory of Infectious Diseases and its Application (Hafner Press, New York, 1975)

8. H. Hethcote, M. Zhien, L. Shengbing, 2002. Effects of quarantine in six endemic models for infectious diseases, Mathematical Biosciences 180, 141160.

9. Muroya, Y.; Enatsu, Y.; Nakata, Y., 2011. Global stability of a delayed SIRS epidemic model with a non-monotonic incidence rate. J. Math. Anal. Appl., 377, 1-14.

10. Mishra, B.K.; Jha, N. SEIQRS model for the transmission of malicious objects in computer network. Appl. Math. Model. 2010, 34, 710-715.

11. Liu, X.; Takeuchi, Y.; Iwami, S., Liu, X.; Takeuchi, Y.; Iwami, S., 2008. SVIR epidemic models with vaccination strategies. J. Theor. Biol. , 253, 1-11.

12. Trawicki, M.B., 2017. Deterministic Seirs Epidemic Model for Modeling Vital Dynamics, Vaccinations, and Temporary Immunity. Mathematics, 5, 7. 
13. Sun, C.; Yang, W., 2010. Global results for an SIRS model with vaccination and isolation. Nonlinear Anal. Real World Appl., 11, 4223-4237.

14. Eckalbar, J.C.; Eckalbar, W.L. Dynamics of an SIR model with vaccination dependent on past prevalence with highorder distributed delay. Biosystems 2015, 129, 50-65.

15. Odagaki, T., 2021. Exact properties of SIQR model for COVID-19. Physica A: Statiscal Mechanics and its Applications, 564, 125564.

16. Mascagni, M.,1990. The backward euler method for numerical solution of the Hodgkin-Huxley equations of nerve conduction. SIAM journal on numerical analysis, 27(4), 941-962. 